\title{
Rancang Bangun Sistem Informasi Penjualan Obat Berbasis Dekstop dengan Model Waterfall
}

\author{
Khairul Rizal \\ AMIK BSI Sukabumi \\ e-mail: khairul.krl@bsi.ac.id
}

\begin{abstract}
Abstrak
Saat ini bidang teknologi khususnya Teknologi Informasi ( $\mathrm{TI}$ ) mengalami kemajuan yang sangat pesat terutama teknologi berbasis komputer. Hampir semua bidang telah menggunakan komputer sebagai alat bantu untuk mendukung evaluasi, analisis, efisiensi, dan efektifitas serta proses pengambilan keputusan dan kebijaksanaan. Seperti halnya dalam sekolahan, perkantoran, perbankan, perusahaan serta dunia bisnis yang memerlukan data yang akurat untuk mendapatkan informasi dalam setiap aktifitasnya. Salah satu yang menjadi kajian penelitian dalam hal ini adalah Apotik Zam-Zam. Dalam pengamatan, penulis melihat proses pengecekan resep, pembayaran masih dibuat secara manual, yang mengakibatkan lambatnya proses pembayaran dan laporan, serta kurang efektif dan efisien. Berdasarkan permasalah tersebut diatas maka peneliti tertarik untuk melakukan penelitian lebih jauh di Apotik Zam-Zam. Dalam penelitian ini peneliti menggunakan metode penelitian pengembangan sistem dengan "Metode Waterfall", serta didukung dengan pengumpulan data melalui cara Observasi, Wawancara dan Studi Pustaka. Berdasarkan hasil penelitian yang telah penulis lakukan maka didapatkan analisa bahwa lambatnya proses transaksi seperti proses pengecekan resep, dan terlambatnya penyampaian laporan dikarenakan banyaknya pekerjaan yang dilakukan dengan manual. Dengan danya sistem informasi penjualan obat yang telah terkomputerisasi akan mempermudah segala aktifitas penjualan dan kesalahan-kesalahan yang terjadi dengan menggunakan sistem yang masih manual dapat diminimalkan
\end{abstract}

Kata Kunci: Metode Waterfall, Teknologi Informasi, Apotik, Teknologi Berbasis Komputer.

\begin{abstract}
Currently the field of technology, especially Information Technology (IT) has progressed very rapidly, especially computer-based technology. Almost all areas have used computers as a tool to support evaluation, analysis, efficiency, and effectiveness as well as decision-making and policy processes. As in schools, offices, banking, companies and businesses that require accurate data to get information in every activity. One of the study studies in this case is ZamZam Apotik. In the observation, the authors looked at the prescription checking process, the payment was still made manually, resulting in slow payment and reporting processes, as well as less effective and efficient. Based on the above problems, the researchers are interested to conduct further research at Zam-Zam Pharmacies. In this research, the researcher uses research method of system development with "Waterfall Method", and supported by data collection through Observation, Interview and Library Study. Based on the results of research that has been done authors then got the analysis that the slow process of transactions such as prescription checking process, and delay of report submission due to the number of work done by manual. With danya drug sales information system that has been computerized will facilitate all sales activities and errors that occur by using a system that still manual can be minimized.
\end{abstract}

Keywords: Waterfall Method, Information Technology, Pharmacy, Computer Based Technology.

\section{Pendahuluan}

Perkembangan dunia informasi saat ini semakin cepat memasuki berbagai bidang baik dalam ilmu dan pengetahuan,

pada saat ini mengalami kemajuan yang sangat pesat terutama teknologi berbasis komputer. Hampir semua bidang telah menggunakan komputer sebagai alat bantu 
untuk mendukung evaluasi, analisis, efisiensi, dan efektifitas serta proses pengambilan keputusan dan kebijaksanaan. Seperti halnya dalam sekolahan, perkantoran, perbankan, perusahaan serta dunia bisnis yang memerlukan data yang akurat untuk mendapatkan informasi dalam setiap aktifitasnya. Dalam lingkungan perusahaan, komputer diperlukan dalam pelayanan transaksi, pembuatan laporan, mempercepat proses kerja serta kemudahan dalam memperoleh informasi yang setiap saat dibutuhkan.

Sistem penjualan yang masih bersifat manual menyebabkan terlambatnya pembuatan laporan (Fachrurozi \& Haryanti, 2017). Penyebab dilakukannya pencatatan secara manual adalah kesalahan dalam pencatatan, kurang akuratnya laporan yang dibuat dan keterlambatan dalam pencarian data-data yang diperlukan (Abdurrahman \& Masripah, 2017).

Sistem penjualan pada apotik zamzam masih menggunakan sistem yang manual, sehingga menyebabkan permasalahan lambatnya proses pengecekan resep, dalam proses pembayaran, setiap nota harus dibuat secara manual, dan itu mengakibatkan lambatnya proses pembayaran dan laporan yang terlambat sehingga tidak cukup mendukung pimpinan untuk membuat keputusan

\section{Metode Penelitian}

\section{a. Metode pengumpulan data}

Untuk memperoleh data yang akurasi dan relevan penulis melakukan teknik pengumpulan data yaitu:

1) Observasi

Dalam hal ini penulis melakukan observasi atau pengamatan langsung pada Apotik Zam-zam.

2) Wawancara

Adalah komunikasi dua arah untuk mendapatkan data dari responden yang dapat dipercaya sebagai masukan untuk melengkapi penelitian ini.

3) Studi Pustaka

Studi Pustaka yang dilakukan,yaitu dengan mempelajari serta mengumpulkan teori-teori yang relevan dengan topik yang dibahas guna memperoleh data serta informasi tertulis yang berhubungan dengan masalah yang dikemukakan.

\section{b. Metode Pengembangan Sistem}

Metode penelitian yang digunakan untuk pengembangan sistem adalah metode waterfall. Metode waterfall digunakan karena mempermudah dalam melakukan pengembangan sistem karena harus melalui tahapan-tahapan yang harus dilakukan (Abdurrahman \& Masripah, 2017).

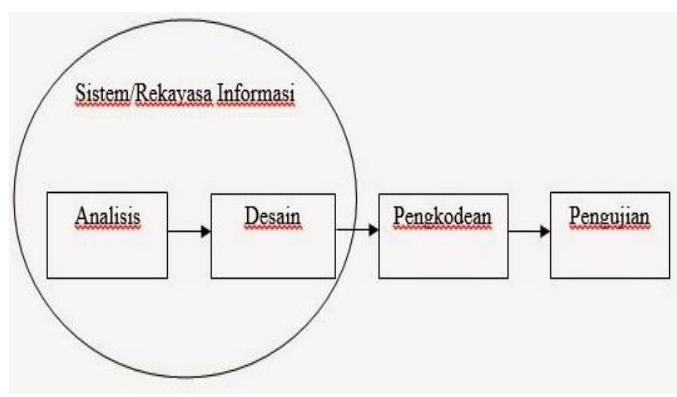

Gambar 1. Model Waterfall

Sumber : (Sukamto \& Shalahudin, 2013)

Tahapan-tahapannya adalah sebagai berikut :

1. Analisis

Merupakan proses pengumpulan kebutuhan sistem informasi. Untuk memahami dasar dari program yang akan dibuat, seorang analisis harus mengetahui ruang lingkup informasi, fungsi-fungsi yang dibutuhkan, kemampuan kinerja yang ingin dihasilkan dan perancangan antarmuka pemakai sistem informasi tersebut. (Fahmi \& Ariani, 2018)

2. Desain

Desain perangkat lunak adalah proses multi langkah yang focus pada desain pembuatan program perangkat lunak termasuk struktur data, arsitektur perangkat lunak, representasi antarmuka, dan prosedur pengodean. Tahap ini mentranslasi kebutuhan perangkat lunak dari tahap analisis kebutuhan ke representasi desain agar dapat diimplementasikan menjadi program pada tahap selanjutnya.

3. Pengkodean

Pengkodean sistem informasi merupakan proses penulisan bahasa program agar sistem informasi tersebut dapat dijalankan oleh mesin (Fahmi \& Ariani, 2018).

4. Pengujian

Pengujian fokus pada perangkat lunak secara dari segi lojik dan fungsional dan 
memastikan bahwa semua bagian sudah diuji. Hal ini dilakukan untuk meminimalisir kesalahan (error) dan memastikan keluaran yang dihasilkan sesuai yang diinginkan.

\section{Hasil dan Pembahasan}

\subsection{Analisa Kebutuhan}

Berdasarkan proses penjualan yang ada, maka tahapan pertama adalah analisa kebutuhan, berikut ini analisa kebutuhan pengguna.

a. Apoteker

1. Apoteker dapat login dan logout

2. Dapat mengelola data obat

b. Kasir

1. Kasir dapat Login dan logout

2. Dapat mengelola data konsumen

3. Dapat mengelola data transaksi

4. Dapat mengelola laporan

c. Pemilik Apotik

1. Dapat login dan logout

2. Dapat melihat laporan penjualan

\subsection{Desain}

Untuk memberikan gambaran yang jelas tentang sistem yang dibangun dibutuhkan rancangan sistem informasi, rancangan database, antar muka untuk memudahkan dalam proses implementasi sistem.

a. Desain Sistem

Desain sistem informasi penjualan obat disajikan dengan menggunakan usecase dan disesuaikan kebutuhan sistem.

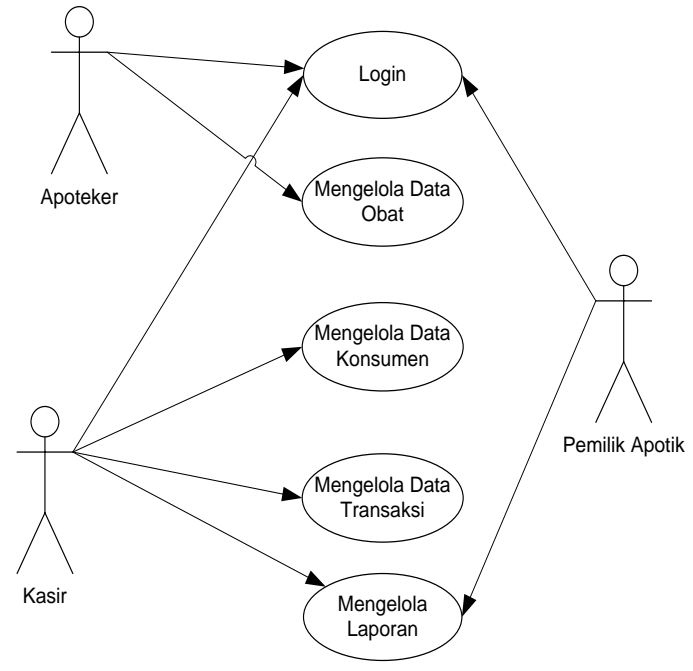

b. Desain Database

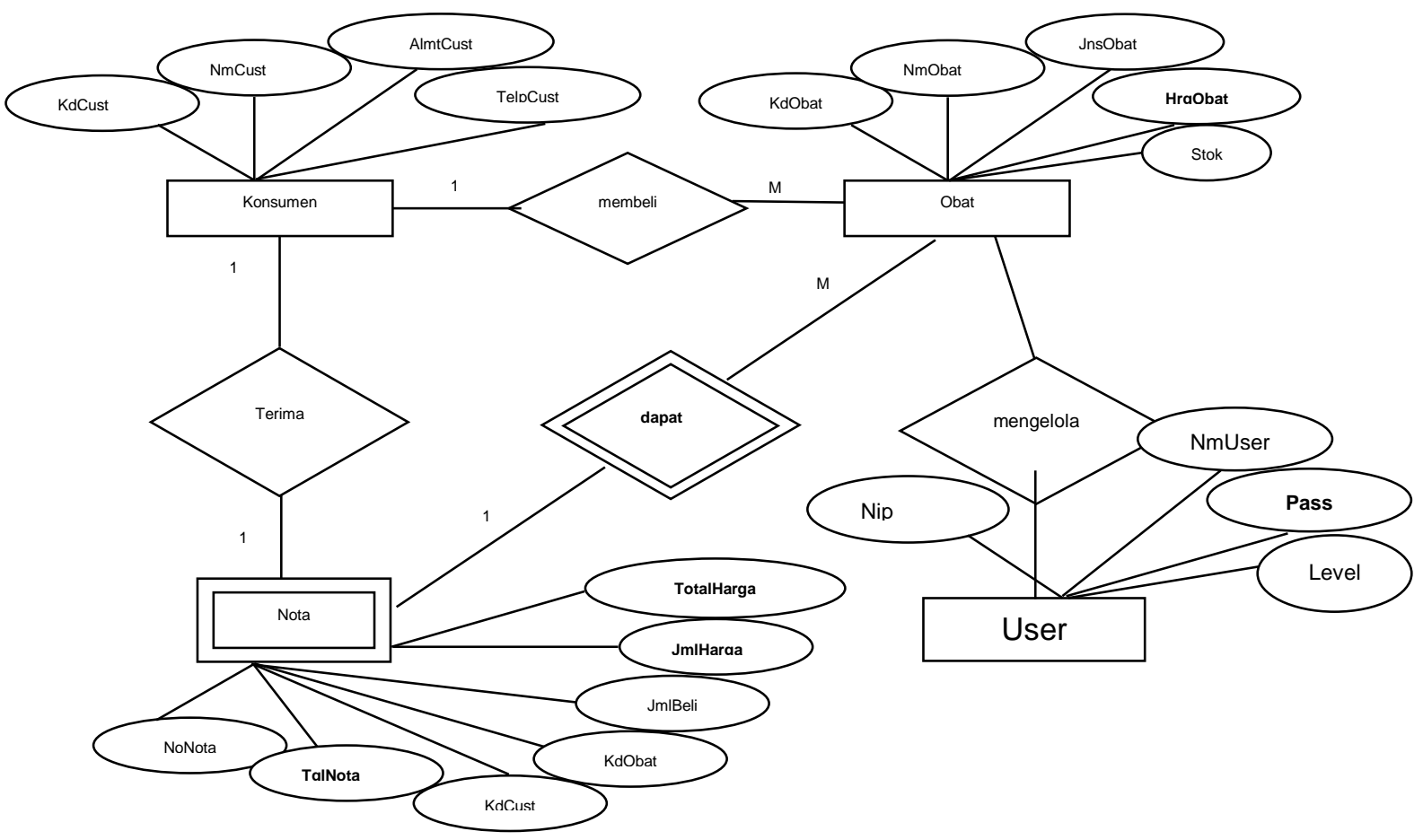

Gambar 3. ERD (Entity Relational Diagram)

Sumber : Rizal (2018) 
c. Desain antar muka

1. Halaman Login

Untuk menggunakan program ini, user harus melakukan login terlebih dahulu.

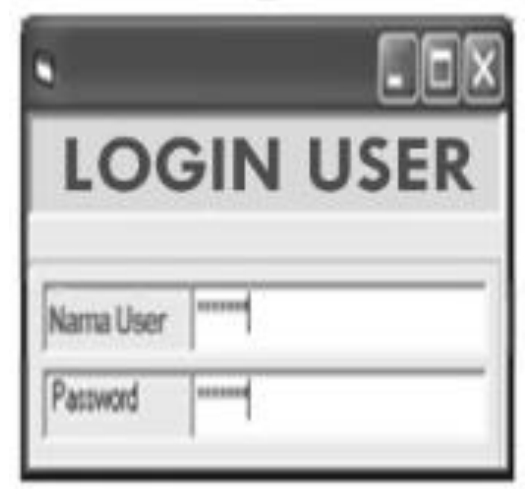

Gambar 4. Halaman Login Sumber : Rizal (2018)

2. Form Data Obat

Halaman atau form data obat berfungsi untuk mengelola data obat, seperti menambah, edit dan menghapus data obat. Berikut ini adalah tampilan form data obat.

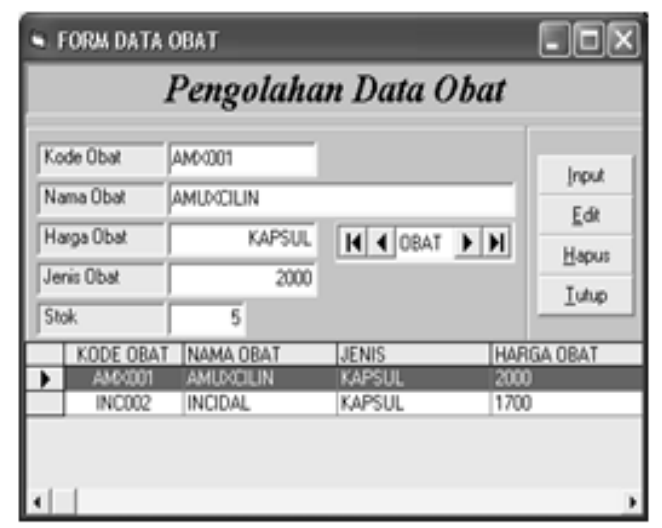

Gambar 5. Form data obat Sumber : Rizal (2018)

3. Form Data Customer

Form data customer hampir sama tampilan dan fungsinya dengan form data obat. Yang membedakannya adalah fungsinya untuk untuk mengelola data customer. Dan berikut tampilannya.

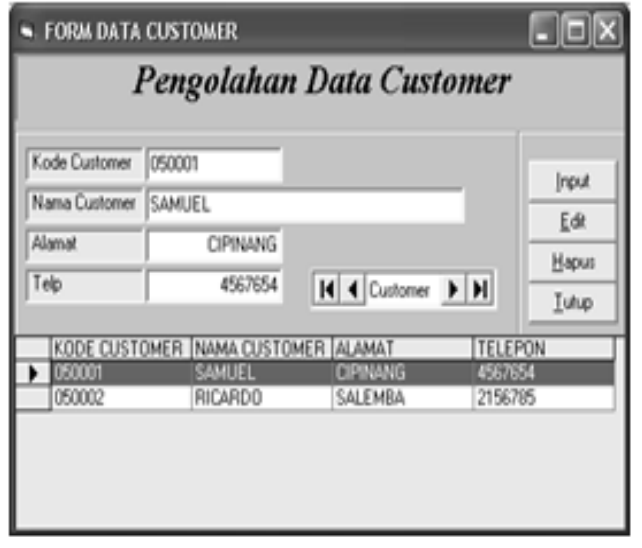

Gambar 6. Form data Customer Sumber : Rizal (2018)

4. Form Transaksi

Form transaksi digunakan apabila ada transaksi penjualan obat.

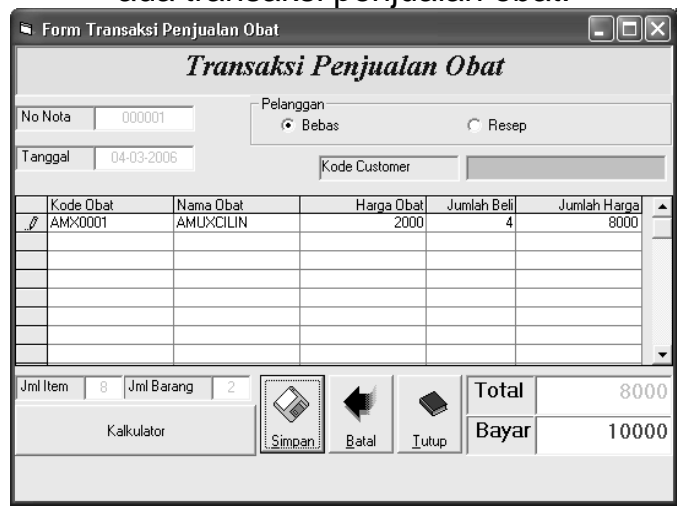

Gambar 7. Form Transaksi Sumber : Rizal (2018)

5. Form Pencarian Data

Untuk mempermudah pencarian data, maka dibuat form untuk pencarian data obat, customer dan data transaksi.

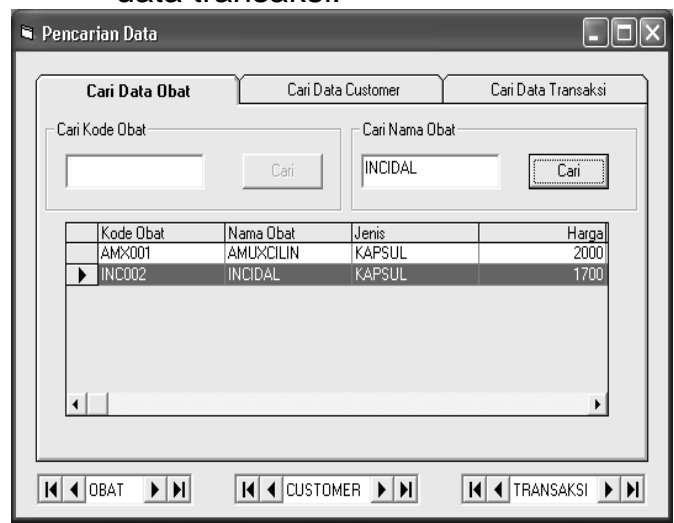

Gambar 7. Form Pencarian Data Sumber : Rizal (2018) 
6. Halaman Laporan

Berikut ini adalah tampilan untuk cetak laporan penjualan obat.

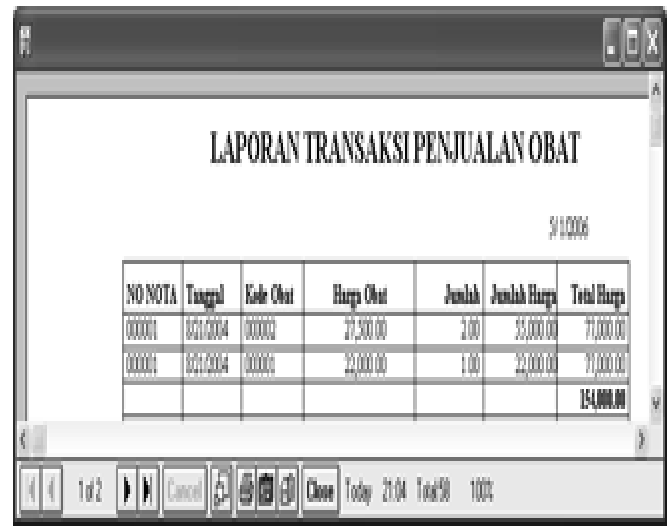

Gambar 8. Cetak Laporan Obat Sumber : Rizal (2018)

\subsection{Pengkodean}

Langkah selanjutnya adalah pengkodean atau coding, Penerapan sistem informasi penjualan ini menggunakan aplikasi visual basic sebagai rancangan programnya. Aplikasi dirancang berbasis dekstop untuk mempermudah pengguna dalam menggunakan sistem informasi penjualan

\subsection{Pengujian}

Untuk tahap pengujian atau testing, penulis menggunakan pengujian dengan metode blackbox, dimana pengujiannya dilakukan pada tampilan program apakah program dapat berjalan dengan baik sesuai yang diinginkan.

Tabel 1. Hasil Pengujian Blackbox Testing

\begin{tabular}{|c|c|c|c|}
\hline Kelas Uji & Skenario Uji & Hasil Yang Diharapkan & Kesimpulan \\
\hline Login Benar & $\begin{array}{l}\text { Masuk username dan } \\
\text { password benar. }\end{array}$ & $\begin{array}{l}\text { Masuk kedalam sistem dan } \\
\text { menu utama, login berhasil. }\end{array}$ & Sesuai \\
\hline Login Salah & $\begin{array}{l}\text { Masukan username dan } \\
\text { password salah }\end{array}$ & $\begin{array}{l}\text { Tidak masuk kedalam sistem, } \\
\text { login salah }\end{array}$ & Sesuai \\
\hline $\begin{array}{l}\text { Form } \\
\text { Obat }\end{array}$ & $\begin{array}{l}\text { Memilih menu obat, } \\
\text { menambah, mengedit, } \\
\text { menyimpan dan } \\
\text { menghapus data obat }\end{array}$ & $\begin{array}{l}\text { Masuk ke form data obat. } \\
\text { Dapat menambah, } \\
\text { menyimpan, mengedit dan } \\
\text { menghapus data obat. }\end{array}$ & sesuai \\
\hline Form transaksi & $\begin{array}{l}\text { Memilih menu transaksi, } \\
\text { menambah,menyimpan } \\
\text { transaksi dan mencetak } \\
\text { nota }\end{array}$ & $\begin{array}{l}\text { Masuk kedalam form } \\
\text { transaksi, } \quad \text { menambah, } \\
\text { menyimpan dan mencetak } \\
\text { nota. Jadi lebih cepat }\end{array}$ & sesuai \\
\hline
\end{tabular}

\section{Kesimpulan}

Setelah melakukan analisa penjualan yang ada di apotik zam-zam dan pengolahan data maka dapat diambil kesimpulan dari hasil penelitian ini lambatnya proses transaksi seperti proses pengecekan resep, dan terlambatnya penyampaian laporan dikarenakan banyaknya pekerjaan yang dilakukan dengan manual. Adanya sistem informasi penjualan obat yang telah terkomputerisasi akan mempermudah segala aktifitas penjualan dan kesalahan-kesalahan yang terjadi dengan menggunakan sistem yang masih manual dapat diminimalkan, sistem yang sudah terkomputerisasi mampu menghasilkan informasi atau keluaran yang lebih tepat dan akurat, dan untuk model pengembangan sistem model waterfall cukup evektif karena langkah-langkahnya mudah untuk diterapkan.

Untuk memberikan saran sebagai alternatif pemikiran dengan harapan, dari segi ilmu pengetahuan tidak bersifat statis tetapi dapat lebih berkembang mengikuti perkembangan teknologi yang terus berkembang dengan cepat. Saran-saran yang dapat disampaikan adalah sebagai berikut: Melakukan backup data secara rutin, agar memiliki cadangan data, Sistem yang dibangun pada intinya hanya sebatas penjualan obat berbasis dekstop jika akan dikembangkan penjualan obat secara juga online.

\section{Referensi}

Abdurrahman, A., \& Masripah, S. (2017). Metode Waterfall Untuk Sistem 
Informasi Penjualan. Information System For Educators And Professionals, 2(1), 95-104. Retrieved from http://ejournalbinainsani.ac.id/index.php/ISBI/article/ view/680/581

Fachrurozi, M. M., \& Haryanti, T. (2017).

RANCANG BANGUN SISTEM

INFORMASI PENJUALAN

PERALATAN PARKING SYSTEM

PADA PT . AUTOPARKING

INDONESIA. Jurnal Pilar Nusa

Mandiri, 13(2), 245-248. Retrieved

from

http://ejournal.nusamandiri.ac.id/ejurn

al/index.php/pilar/article/view/687

Fahmi, M., \& Ariani, F. (2018). Rancang

Bangun Sistem Informasi Akademik

Berbasis Web Dengan Metode

Waterfall. SinkrOn, 2(No 2), 119-124.

Retrieved from

http://jurnal.polgan.ac.id/index.php/sin

$\mathrm{kron} / \mathrm{article} / \mathrm{view} / 124$

Sukamto, R. A., \& Shalahudin, M. (2013).

Rekayasa Perangkat Lunak

Terstruktur dan Berorientasi Objek.

Bandung: Informatika. 